\title{
CAUSA \& EFEITO: OBJETO DE APRENDIZAGEM PARA AUXÍLIO À ELICIDAÇÃO DE REQUISITOS DE SUSTENTABILIDADE
}

\author{
Carlos V. da Silva, MSC. (UNIRITTER); Vinicius G. Ribeiro, Dr. \\ (UNIRITTER); André da Silveira, Dr. (UNIRITTER)
}

\section{RESUMO}

PALAVRAS CHAVE

Design para Sustentabilidades, Educação para o Design, Game Design, Abordagens Projetuais.

KEYWORDS

Design for Sustainabilities, Education for Design, Game Design, Projective Approaches.

\begin{abstract}
O presente artigo é o resultado de estudos e considerações sobre a prática profissional do designer de produto orientado pelos parâmetros do desenvolvimento sustentável. Como prova de conceito, propõe-se o desenvolvimento de um objeto de aprendizagem, expresso através de um processo em uma ferramenta lúdica — um jogo — que auxilie designers e projetistas a considerarem requisitos sustentáveis durante a fase de projetação. Essa pesquisa investiga a relação do designer de produto com a problemática relacionando as dimensões ecológica, social e econômica. Com este estudo, percebe-se que somente a educação para a sustentabilidade pode assegurar que certos paradigmas mercadológicos, tais como o crescimento quantitativo contínuo possam ser superados.
\end{abstract}

\section{ABSTRACT}

This paper is the result of studies and considerations of professional practice of product designer guided by sustainable development parameters. As proof of concept, an object of learning was developed expressed through a process in a playful tool - a game - that helps designers and designers to consider sustainable requirements during the design stage. This research investigates the product designer's relationship with the problems relating the ecological, social and economic dimensions. With this study, it is clear that only the education for sustainability can ensure that certain market paradigms, such as the continued quantitative growth can be overcome. 


\section{INTRODUÇÃO}

Segundo os conceitos do construtivismo interacionista, os seres humanos não são apenas um produto da natureza, nem um mero resultado de suas disposições internas, e sim uma construção própria que se reproduz, dia após dia, como resultante da interação entre esses dois fatores. O conhecimento não se encontra isolado no sujeito nem mesmo em um objeto: ele se constrói durante a interação do indivíduo com o objeto (meio). Na proporção em que o indivíduo interage com os objetos é que este produz a capacidade para conhecer e produzir o próprio conhecimento - esse surge a partir da ação (BECKER, 2001; CARRETERO, 1997; GOULART, 1997; PIAGET 1982).

Nesse contexto de ensino e aprendizagem é válido considerar os jogos como uma ferramenta importante para o crescimento intelectual do ser humano, pois conforme Alves e Bianchin (2010), as atividades lúdicas estão diretamente ligadas ao desenvolvimento social, criativo, afetivo e cultural. De acordo com Piaget (1976), as atividades lúdicas são um berço essencial para as atividades intelectuais dos seres humanos, e não somente uma forma de entretenimento e descontração, representando um estado que contribui para o desenvolvimento intelectual. Os jogos favorecem a aprendizagem por normalmente incidirem em ambientes de familiaridade, onde existe pouca tensão para se experimentar atitudes que em outros contextos seriam intimidadas pelo receio ao erro e a punição (KISHIMOTO, 1998).

O atual panorama social apresenta uma cultura predominante estruturada sob condições de consumo intenso e generalizado. Esta fase, definida como modernidade reflexiva, fluida, de risco, é determinada por profundas mudanças sociais - um período de desenvolvimento em que os riscos ambientais, sociais, econômicos e políticos tendem a escapar do controle a qualquer instante, podendo originar inúmeros transtornos caso não aconteça algum tipo de mudança (BAUMAN, 2009; BECK, 1997; FRY, 2011; MANZINI, VEZZOLI, 2002). A chamada vida líquida se caracteriza por constantes incertezas: uma vida precária, onde o lixo gerado - em grande parte, como consequência dessa situação de extremo consumo - é, comprovadamente, o subproduto atual de maior abundancia. Mas, conforme Bauman $(2009 ; 2010)$, ainda há tempo para refletir e propor mudanças no caminho a ser seguido, no intuito de transformar esse trauma econômico, centrado no consumidor e baseado no excesso de ofertas e no envelhecimento cada vez mais acelerado dos bens de consumo.

Sob tal situação, já é de extrema relevância que o designer contemporâneo assuma novas posições estratégicas no elo entre a indústria, que produz e comercializa bens de consumo e a sociedade, que os utiliza e descarta cada vez em maiores quantidades. Este profissional criativo, além de projetar, gradativamente deverá atuar de um modo político pedagógico, conscientizando clientes, consumidores e a sociedade de um modo geral sobre à importância das questões ambientais e sociais, propondo possíveis soluções inovadoras centradas nas reais necessidades dos seres humanos.

Conforme Cross, Christiaans e Dorst (1996), os designers estão imersos nesta cultura material com habilidades para interpretar as mensagens que os objetos comunicam, e então criar novos objetos com novas mensagens. Entretanto surgem questões simples, porém vitais, que necessitam de respostas: considerando o atual estado insustentável do planeta, o que ativistas políticos e designers (bem como todos os profissionais que tomam decisões projetuais) podem fazer e quais rumos devem ser seguidos? De acordo com Veiga (2013), os países desenvolvidos que apresentam os menores índices de desigualdades - os quais servem como modelo de sustentabilidade - são os que sistematicamente apresentam melhores desempenhos nas dimensões sociais mais relevantes para a qualidade de vida, como coesão social, dependências químicas, saúde pública, doenças mentais, educação, encarceramentos, longevidade, mobilidade social, obesidade, partos de adolescentes, vida comunitária e violência. Acrescenta ainda que em algumas destas nações, além de menos desigualdades, há também menores índices de consumo, mais reciclagem e maior ajuda externa a países subdesenvolvidos.

Conforme Chick e Micklethwaite (2011, p. 78, tradução nossa), é preciso "olhar para o futuro, aprendendo com o passado. Um compromisso com o 'progresso' humano pode ser perigoso se esquecermos de aprender com nosso passado". De acordo com os autores, o termo sustentabilidade engloba um conjunto complexo de ideias, podendo abraçar quase todos os aspectos da consciência humana e responsividade às responsabilidades e impactos ecológicos, sociais e econômicos. A sustentabilidade é, portanto, difícil de colocar em poucas palavras. Como resultado, pode ser confuso para os projetistas (e demais profissionais envolvidos nos processos de produção de artefatos) saberem a melhor forma de agir em resposta a uma maior conscientização sustentável. A sustentabilidade é, por vezes, reduzida a questões individuais, que podem ser perigosas 
se distraírem os olhares das questões maiores. Corre-se o risco de colocar o foco em algumas questões amplamente visíveis, mas realmente muito menores, e não abordar, por exemplo, os impactos ambientais e sociais globais dos nossos estilos de vida, organizações e vizinhança.

Buscando intervir nesse contexto, os objetivos do presente artigo consistem em desenvolver e testar um objeto de aprendizagem, expresso através de um processo em uma ferramenta lúdica - um jogo - que auxilie o projetista a considerar requisitos sustentáveis durante a fase de projetação.

De acordo com a taxonomia proposta por Sampieri, Collado e Lucio (1991), este trabalho é classificado - segundo seus objetivos gerais - como uma pesquisa descritiva, em que o pesquisador descreve situações, especificando propriedades importantes de indivíduos, grupos, comunidades ou qualquer outro fenômeno que esteja sob análise, visando aprimorar ideias e proporcionar novas descobertas, com o intuito de formular soluções mais precisas ou alternativas para estudos posteriores. Esse projeto está orientado sob uma abordagem qualitativa envolvendo levantamento teórico e a proposição de uma prova de conceito, expressando o objetivo de produzir conhecimento relevante em termos práticos (FLICK, 2009).

\section{DESENVOLVIMENTO}

Com o intuito de estabelecer o estado da arte sobre técnicas, formas e diretrizes a respeito dos métodos e fatores do design sustentável, inicialmente realizou-se o levantamento bibliográfico para estabelecer a fundamentação teórica a cerca dos temas que permeiam o assunto geral: 1) objetos de aprendizagem; 2) fatores e métodos projetuais; 3) sustentabilidade; e 4) jogos. A pesquisa bibliográfica foi conduzida em livros, periódicos, dissertações, teses e anais de eventos, nacionais e internacionais. Para analisar os dados coletados e produzidos foram utilizadas técnicas de codificação e categorização, análise de conversação, conteúdo, discursos e documentos (FLICK, 2009; SILVERMAN, 2009).

Após a sistematização dos dados, apresenta-se uma prova de conceito seguindo o Método de Design de Sistemas para a Sustentabilidade (MSDS - Method for System Design for Sustainability), proposto por Vezzoli (2010). O MSDS apresenta uma estrutura flexível e modular dividida em cinco estágios principais: 1) análise estratégica, com o objetivo de obter informações necessárias para instrumentalizar a geração de ideias sustentáveis; 2) exploração de oportunidades, onde o objetivo principal é catalogar as possíveis estratégias promissoras e disponíveis,listando cenários para a orientação de projetos sustentáveis; 3) desenvolvimento de conceitos; 4) detalhamento do sistema, descrevendo o conceito gerado mais promissor para sua implementação; e 5) comunicação, evidenciando as características sustentáveis do objeto/sistema em questão (VEZZOLI, 2010).

O desenvolvimento estrutural da prova de conceito orientou-se pela metodologia Playcentric Design Process, proposta por Fullerton (2008), que acredita que a chave principal para converter um conceito inicial de jogo em uma experiência satisfatória com jogabilidade elevada, está relacionada com um processo sólido de desenvolvimento. O método está dividido em três partes: 1) Definir os objetivos da experiência do agente - a melhor forma, segundo o autor, para aproximar o jogador com o processo de desenvolvimento do jogo é definir quais serão os seus objetivos e suas experiências de jogo. Isso significa procurar estabelecer quais os tipos de experiências os jogadores irão experimentar durante a partida. Como por exemplo, "os jogadores sentirão um senso de felicidade ao invés de competitividade", ou ainda "para ganhar os jogadores deverão cooperar"; 2) Prototipar e testar - executar um protótipo rudimentar do jogo para testar a jogabilidade e as funções esperadas durante a partida o quão cedo for possível. Começar um projeto sem que todos os aspectos estejam bem definidos pode resultar em fracasso; e 3) Iteração - por essa taxonomia, o autor sugere o processo de projetar, testar e avaliar os resultados, repetidas vezes, buscando melhorar a jogabilidade e os recursos do jogo.

\subsection{Análise Estratégica}

Os objetivos e expectativas do objeto de aprendizagem proposto consistem em possibilitar ações cooperativas e aproximar os estudantes projetistas com os assuntos relacionados à sustentabilidade no desenvolvimento de suas atividades, mais especificamente, no que diz respeito ao estabelecimento de requisitos sustentáveis em projetos. As práticas cooperativas, por proporcionarem o confronto de ideias e pontos de vista, acabam favorecendo também o surgimento de soluções alternativas para a resolução de um mesmo problema. $\mathrm{O}$ ambiente lúdico e descontraído evidenciado pelas situações de jogo, aliado ao uso compartilhado de conteúdo apresenta-se como uma importante ferramenta para privilegiar descobertas e experimentações.

Considerar aspectos sustentáveis em projetos, no 
Brasil, ainda apresenta-se apenas como uma opção frente à competitividade do mercado, mas a decisão final sobre o que será de fato produzido acaba sendo influenciada, na maioria das vezes, pelo fator mercadológico. Isso não significa que os designers não devam considerar tais questões. Quanto mais profissionais educados para as questões de sustentabilidade estiverem exercendo suas atividades, gradativamente esses assuntos e características tendem a se disseminarem dentro das empresas e organizações.

Sob os parâmetros do design instrucional e do desenvolvimento sustentável, extraíram-se possíveis requisitos projetuais do referencial pesquisado, os quais foram categorizados em quatro grupos distintos (Quadros 1,2,3e4)

Quadro 1 - Aspectos Ecológicos.

\begin{tabular}{|l|c|} 
Requisitos & Síntese \\
\hline Resiliência & Como você se prepara para as possíveis mudanças de cenário? \\
\hline Ciclo de vida & Feche o ciclo. \\
\hline Lixo & Zero Reduzir, reusar, reparar, recilar, valorizar o ciclo. \\
\hline Eficiência energética & Onde você pode economizar energia? \\
\hline Mudança climática & Como seu projeto afeta o planeta? \\
\hline Obsolescência & Como seu objeto desafia a durabilidade? \\
\hline Processos & $\begin{array}{c}\text { Quais são os processos produtivos que você irá utilizar? } \\
\text { Eles são ecologicamente corretos? }\end{array}$ \\
\hline Toxinas & Detectar e Eliminar. \\
\hline Materiais & $\begin{array}{c}\text { Quais são os materiais que você irá precisar e como } \\
\text { eles afetam o meio ambiente. }\end{array}$ \\
\hline Falso "verde" & Você es'ta contando a história completa? \\
\hline Embalagem & O que acontece quando o objeto é desembalado? \\
\hline Bens comuns & Como você promove a segurança aliementar \\
& e preserva o area \\
\hline Comida água.
\end{tabular}


Quadro 2 - Aspectos Sociais

\begin{tabular}{|c|c|}
\hline Requisitos & Síntese \\
\hline Desmaterialização & $\begin{array}{l}\text { Como seu projeto contribui para o estabelecimento de } \\
\text { uma sociedade menos comunista? }\end{array}$ \\
\hline Revolução & Qual será a próxima revolução? \\
\hline Conhecimento & Quem precisa aprender o quê? \\
\hline Benefícios & Quem ganha o quê? \\
\hline Lifestyle & O que é um esitlo de vida sustentável para você? \\
\hline Envolvimento local & Você está pensando global e agindo local? \\
\hline Local de trabalho & Como melhorar o seu ambiente de trabalho? \\
\hline Discriminação & Como você pode eliminar esse fantasma? \\
\hline Comportamento & O que deve ser mudado e como? \\
\hline Igualdade de gênero & Como você promove igualdade em todos os níveis? \\
\hline Moral e ética & Qual é seu código de conduta? \\
\hline Felicidade & Como você define e promove a felicidade \\
\hline Política e design & Seu projeto pode influenciar o cenário político atual e futuro? \\
\hline Stakeholders & $\begin{array}{l}\text { Como você pode envolver as partes afetadas; interessadas } \\
\text { por suas ações. }\end{array}$ \\
\hline Responsabilidades & Como você divide o trabalho. \\
\hline Usuário & Como seu projeto considera a participação do usuário? \\
\hline Coletivo & Seu projeto é para uso individual ou coletivo? \\
\hline Direitos Humanos & $\begin{array}{l}\text { Como você pode ter certeza que está cumprindo com } \\
\text { os direitos humanos? }\end{array}$ \\
\hline Cultura & Seu projeto valoriza cultura local? \\
\hline Adaptabilidade & Seu projeto é adaptável para todas as necessidades? \\
\hline Diversidade & Etnia, idade, cultura, LGBT, religião, sexo, deficiência. \\
\hline Recursos livres & Exploração X lucros \\
\hline Crescimento & Considerando um crescimento sustentável,quanto é o suficiente? \\
\hline Saúde & Como você promove uma boa saúde? \\
\hline Corrupção & Como você pode trabalhar contra a corrupção. \\
\hline
\end{tabular}

Quadro 3 Questões Econômicas

\begin{tabular}{|l|l|}
\hline Requisitos & Síntese \\
\hline Finanças responsáveis & Como você analisa o impacto dos seus investimentos? \\
\hline Situação atual & Como está a sua situação atual? \\
\hline Rentabilidade & Oportunidades a curto e longo prazo. \\
\hline Comunicação & Qual é a sua estratégia de comunicação? \\
\hline Transparência & Você está escondendo algo? \\
\hline Cadeia de suprimentos & Analise a sua cadeia de suprimentos. \\
\hline Tecnologias & $\begin{array}{l}\text { Você está atualizado em relação às novas tecnologias que } \\
\text { que podem afetar seu projeto? }\end{array}$ \\
\hline Inovação \\
Liderança & $\begin{array}{l}\text { O que você precisa para encontrar novas soluções? } \\
\text { Como sua liderança pode incentivar a mudnaça positiva? }\end{array}$ \\
\hline S.W.O.T & Forças X fraquezas; ameaças x oportunidades. \\
\hline Logística & Como você pode se aproximar do menor impacto possível? \\
\hline Animais & Como seu projeto promove a proteção aos animais? \\
\hline
\end{tabular}




\begin{tabular}{|l|l|}
\hline Requisitos & Síntese \\
\hline Objetivos & O que o projeto está visando? \\
\hline Atores & Quem são as pessoas fundamentais para o bom funcionamento do projeto? \\
\hline Métricas & Possíveis resultados financeiros,impacto socieal e ambiental. \\
\hline Ideia & Qual a ideia central que sustenta o projeto? \\
\hline Questão foco & Questão que está sendo resolvida. \\
\hline Motivação & Coisas que mantém seu time inspirado. \\
\hline Tendências & Para qual lado as coisas estão indo? \\
\hline Background & Como e porquê o projeto se originou? \\
\hline Exclusividade & O que torna o projeto único? \\
\hline Aspectos legais & Quais são as principais questões legais que seu projeto terá que enfrentar? \\
\hline Marcos & Como organizar checkpoints ao longo do caminho? \\
\hline Dificuldades & Quais podem ser as circunstâncias de contenção? \\
\hline Lugares & Onde o projeto será executado? \\
\hline Modelos & Onde você encontra inspiração? \\
\hline Competências & Conjunto de conhecimentos, habilidades e atitudes que seu projeto demanda. \\
\hline Valores & Seus princípios fundamentais? \\
\hline Visão & Descreva seu proejto em 2, 10 e 100 anos. \\
\hline Perspectivas & O que você vê no horizonte? \\
\hline Limites Planetários? & Você pode agir como defensor da Terra? \\
\hline Desafios & Existem dificuldades em seu projeto? \\
\hline Riscos & Quais são os seus riscos ambientais, sociais e econômicos? \\
\hline
\end{tabular}

Na sistematização dos dados buscou-se abordar os requisitos levando-se em conta como esses aspectos poderiam ser inseridos no contexto de jogo. Para a composição de conceitos, primeiramente estabeleceu-se um valor para os dados categorizados anteriormente considerando o padrão de desenvolvimento sustentável no sentido forte, proposto por Bosselmann (2009), onde as questões ecológicas são superiores as questões sociais, e estas prevalecem sobre as questões econômicas. Esse valor, quando transferido ao objeto de aprendizado, representa a soma que definirá o vencedor da partida. Assim a pontuação ficou distribuída da seguinte maneira: as casa do tabuleiro com as questões ecológicas receberam 3 e 4 pontos, as questões sociais 2 pontos, os aspectos econômicos 1 ponto e os atributos projetuais não somam pontuação.

\subsection{INTERATION PROCESS}

Contemplando o processo de desenvolvimento de jogos proposto por Fullerton (2008), partiu-se pela geração rudimentar de ideias para possíveis tabuleiros. Optou-se por desenvolver o objeto de aprendizagem em forma de um jogo de tabuleiro por representar um resgate às origens das antigas civilizações do 'velho mundo', período de relevante avanço do desenvolvimento tecnológico, cultural e socioeconômico. Após formalizou-se a ideia mais promissora, condizente com o contexto. Mais uma vez optou-se pelo modelo de desenvolvimento sustentável no sentido forte proposto por Bosselman (2009) para orientar a forma do tabuleiro - representado na Figura 01.

Figura 1 - Formalização da ideia

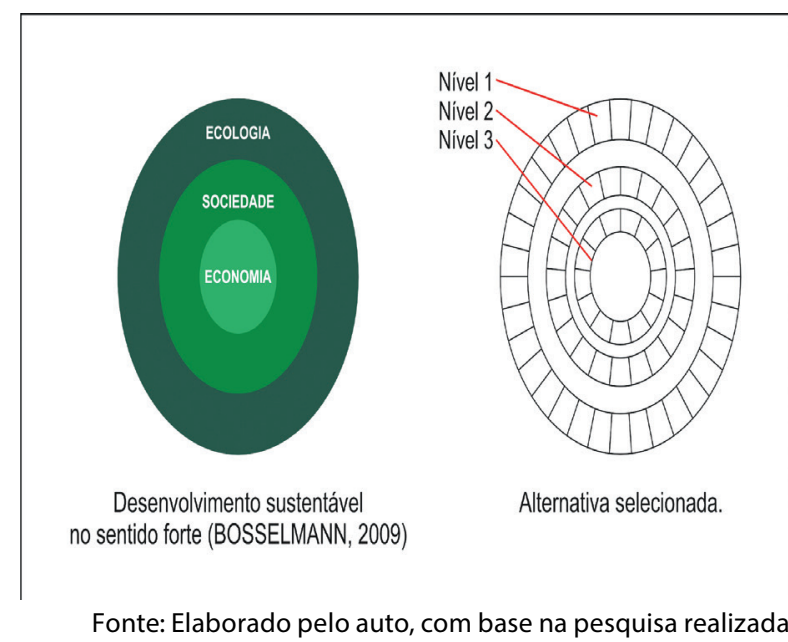


Após a seleção do tabuleiro, distribuíram-se as categorias de requisitos antes codificadas, na medida em que as questões ecológicas, por valerem mais pontos, foram alocadas no Nível 1. O Nível 2 apresenta maior ênfase nos aspectos relacionadas a esfera social e o Nível 3 as questões econômicas. As questões de características projetuais foram distribuídas entre os três níveis.

Para validar a eficiência da ferramenta proposta, coletar dados referentes ao seu uso e identificar possíveis pontos de ajustes, realizou-se uma experiência de uso com grupo focal de alunos de Design, de uma instituição de ensino superior de porte médio do estado do Rio Grande do Sul, no semestre 2014/B. Os participantes do grupo focal testaram o jogo por um período de 45 minutos, enquanto foram filmados para posterior análise. Após o teste os voluntários responderam um questionário sobre os aspectos definidos por Santarosa e Conforto (2012) para avaliação de objetos de aprendizagem em relação à qualidade do uso, conteúdo e acesso.

Buscando corrigir os problemas estruturais encontrados com o teste executado, contemplando o processo de interação (FULLERTON, 2008), desenvolveu-se um segundo protótipo conforme ilustrado na Figura 02.

Figura 1 - Formalização da ideia

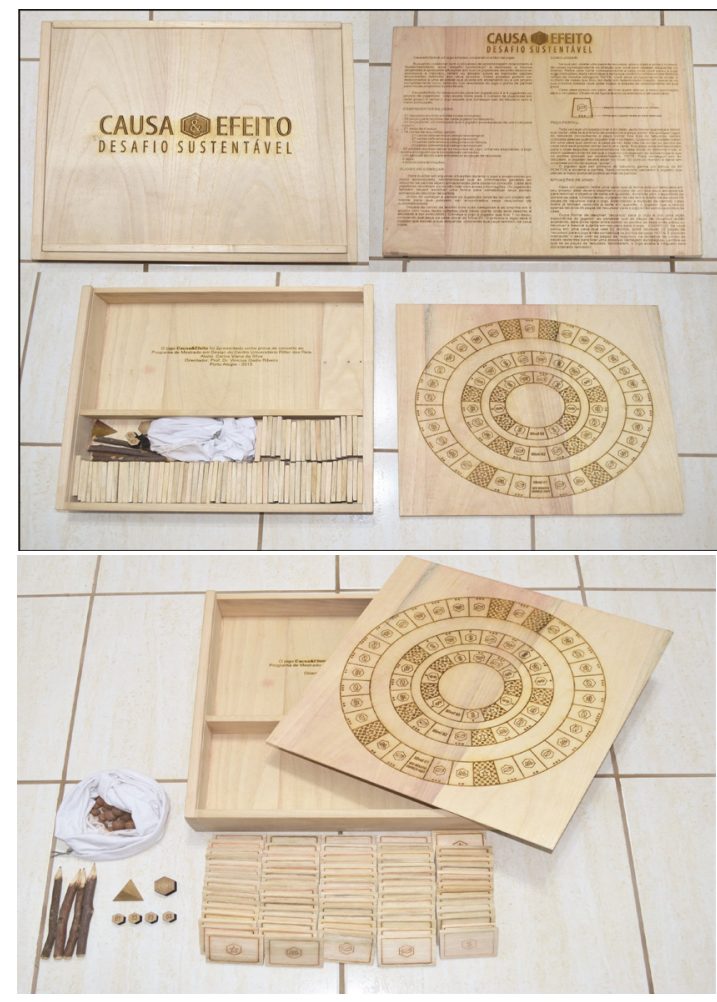

Fonte: Elaborado pelo auto, com base na pesquisa realizada.

\subsection{Detalhamento}

Na tentativa de produzir um artefato causando o mínimo de impacto ambiental possível, optou-se por elementos naturais em sua composição. Para a embalagem e tabuleiro utilizou-se a madeira popularmente conhecida como Quiri (Paulownia - gênero arbóreo da Família Scrophulariaceae). A árvore de Quiri é originária do leste da Ásia, e se desenvolve em zonas subtropicais e tropicais. A principal característica desta madeira é sua leveza e boa resistência, o que a torna amplamente utilizada em móveis, construção de casas e instrumentos musicais (LORENZI et al., 2003; BONNER, BURTON, 1974). Procurando utilizar o mínimo possível de matéria prima virgem no processo produtivo, para o desenvolvimento das cartas do jogo, dado e demais peças utilizaram-se pedaços de madeira que seriam descartados por uma indústria do ramo de paletes. Estes foram cortados e usinados nos tamanhos necessários.

Os elementos gráficos e textuais contidos nas peças, tabuleiro e as instruções de jogo foram produzidos pelo processo de corte/gravação a laser a base de dióxido de carbono, que funciona fundamentado nas leis da interação da radiação luminosa com o material. Devido sua elevadíssima precisão geométrica, esse processo tem-se aplicado para diversas finalidades (ALLISON et. al., 2008). Quando se comparado com outros os processos de impressão a base de pigmentos, no corte a laser não há o emprego de substâncias tóxicas como na maioria das tintas nem o uso da água para sua produção. A marcação se dá através da vaporização da matéria prima existente.

As pedras que representam os recursos do jogo são feitas de argila expandida. Conforme Moravia et al. (2006), este material é um produto oriundo do aquecimento de certos tipos de argila a temperaturas próximas a $1200^{\circ} \mathrm{C}$. As principais vantagens dessa argila são a alta durabilidade, baixa densidade, baixo custo e também se apresenta quimicamente inerte. Para armazená-las utilizou-se um saco de tecido de algodão. Para que os jogadores anotassem as informações geradas para posterior consulta, utilizaram-se blocos feitos com papel reciclado e lápis produzidos a partir de galhos de podas de eucalipto, produzidos por um artesão local.

Para finalizar o método de design de sistemas sustentáveis, Vezzoli (2010) sugere que se execute a comunicação do que foi produzido. O presente artigo representa a comunicação do objeto de aprendizagem desenvolvido, evidenciando as características do objeto/sistema em questão. 


\section{CONCLUSÃO}

A presente pesquisa teve como objetivo o estudo dos objetos de aprendizagem, das metodologias de design, dos fatores projetuais, dos conceitos e diretrizes sobre o desenvolvimento sustentável e game design, para então desenvolver-se uma prova de conceito - um objeto de aprendizagem, expresso através de um processo em uma ferramenta lúdica que auxiliasse o projetista a considerar requisitos sustentáveis durante a fase de projetação. De forma a atender os objetivos propostos, a codificação e categorização do conteúdo serviu de extrema relevância para se esclarecerem os requisitos de sustentabilidade, sendo possível identificá-los e sistematizá-los com maior clareza.

Diante do atual cenário insustentável em que a maioria das sociedades se encontra, fica evidente a importância em considerar tais requisitos durante a fase de projetação. Desenvolver um projeto de caráter sustentável confirma o papel do designer como agente modificador diante de uma sociedade que enfrenta grandes problemas ambientais, sociais, econômicos e políticos. É preciso a conscientização dos profissionais da área para que projetem e desenvolvam produtos com um menor impacto ambiental, social e com maior valor econômico agregado. Frente à complexidade das variáveis que envolvem projetos sustentáveis, é válido o estudo e a proposição de novas abordagens projetuais voltadas ao contexto da sustentabilidade.

Com ações inteligentes e criativas, o designer contemporâneo pode proporcionar inúmeras alternativas para minimizar os impactos dos seres humanos na Terra, principalmente com relação às questões ambientais - que se tornam evidentes em função do elevado grau de descarte de objetos, quando muitos materiais acabam não sendo reciclados ou utilizados por indisponibilidade técnica ou projetual. Estender a vida útil de um produto ou Ihe atribuir uma segunda função representa apenas uma pequena fração do que o desenvolvimento de produtos centrados na sustentabilidade pode oferecer.

Para que se consiga atingir tais objetivos, é fundamental a participação do designer em todas as etapas do processo projetual, desde as determinações iniciais de pré-requisitos, formação de conceitos até as etapas de produção e pós-produção, estreitando a ligação do setor de criação com os setores administrativos/produtivos. Em virtude disto, seria interessante que os profissionais da área se capacitem cada vez mais ao ponto de perceberem, de qual maneira o resultado do seu trabalho possa influenciar o modo de consumo atual da sociedade, gerando ideias e promovendo atitudes sustentáveis.

O atual cenário social exige das instituições e organizações novos métodos de projetar e gerenciar processos, organizar habilidades, desenvolver pesquisas, criar modelos e sistemas, sendo assim, se faz necessário que se desenvolvam novas estruturas e abordagens para os processos de ensino-aprendizagem. A emergência de teorias coerentes em torno da evolução do pensamento em design contribui para que sejam percebidas novas formas de ensinar e novas formas de praticar o design.

Diante da situação lúdica proporcionada pelo objeto de aprendizagem, durante o teste executado com os alunos de design, foi possível perceber de forma qualitativa que a ferramenta naturalmente despertou a cooperação entre estudantes. Assim que um jogador lia a carta com as instruções da vez, logo os demais participantes começavam a dar palpites e sugestões, favorecendo o surgimento de novas ideias e conexões relacionadas ao projeto em questão, estimulando o confronto de visões. Porém, percebeu-se que o tempo de 45 minutos (aproximadamente uma hora-aula) foi pouco para executar-se uma partida inteira, pois os jogadores mal haviam chegado à metade do tabuleiro. Durante a execução do teste ainda foi possível perceber que o jogo, por proporcionar um ambiente descontraído, favoreceu o processo de ensino estimulando a reorganização mental das informações referente aos projetos em questão ao incitar o pensamento divergente, o confronto e a argumentação, evidenciando formas alternativas para resolução de um mesmo problema.

Sobre às questões determinadas por Santarosa e Conforto (2012) para a avaliação de objetos de aprendizagem, segundo o questionário respondido pelos alunos que testaram o jogo, a proposta foi considerada:

- Com relação à qualidade de uso - visualmente atraente, de fácil utilização, extremamente interativa, com instruções claras, capaz de fornecer ajuda ao usuário, flexível e reutilizável permitindo o controle pelos usuários.

- Com relação à qualidade de conteúdo - foi interpretado como claro e conciso, relevante, com linguagem simples e objetiva, apresentando os objetivos do objeto de aprendizagem em questão, identificando conhecimentos prévios, relacionando muitos conceitos, reforçando os conteúdos progressivamente e fornecendo documentação para o educador.

- Com relação à qualidade do acesso - o objeto de aprendizagem não apresenta conteúdo em libras e tam 
bém não é compatível com tecnologias assistivas, porém apresenta descrição para conteúdo não textual, revela o uso adequado de cores e fontes, fornece orientação ao usuário e não requer a instalação de programas virtuais.

Nesse sentido a presente pesquisa contribui para o tema sobre game design, objetos de aprendizagem e sustentabilidade, na medida em que o processo de iteração - um dos elementos chave no desenvolvimento de jogos, que consiste em projetar, testar e avaliar os resultados, inúmeras vezes buscando melhorias - pode ser replicado no âmbito do ensino de design sustentável, porém com o foco no estabelecimento dos requisitos projetuais, ao ponderar repetidas vezes e sob diferentes perspectivas tais questões. Contudo percebeu-se que o emprego de requisitos de sustentabilidade em projetos não está atrelado ao uso de determinadas metodologias ou a falta de ensino sobre tais questões no ambiente de sala aula, e sim pelo não estabelecimento dos requisitos adequados durante as fases iniciais de projetação, em especial a fase de informação. Mesmo o designer tendo acesso a inúmeras ferramentas projetuais para auxiliar no processo de inovação, somente a educação para a sustentabilidade pode assegurar que certos paradigmas mercadológicos (como o crescimento quantitativo contínuo, por exemplo) possam ser superados.

Como trabalho futuro, estima-se a viabilização mercadológica do conceito desenvolvido para que possa ser distribuído em diversos centros universitários, proporcionando mais situações em que o jogo possa ser utilizado e analisado sob diferentes perspectivas. Pretende-se também continuar o desenvolvimento do objeto de aprendizado proposto, porém convertido para uma plataforma digital, facilitando sua reutilização e divulgação. Com o auxílio do ambiente em rede, as respostas e dados obtidos durante o decorrer do jogo podem ser armazenadas em um grande repositório virtual, formando assim um banco de dados sobre requisitos de sustentabilidade em projetos, podendo ampliar ainda mais o compartilhamento do conteúdo e promover a interação entre estudantes de diversas localidades. Sugere-se também para que, em trabalho futuro para o desenvolvimento do produto, seja considerado o uso de tecnologias assistivas e o emprego dos alfabetos em braile e libras, para inclusividade a essa ferramenta.

\section{REFERÊNCIAS}

1. ALLISON, R. R. et. al. Bio-technology and photodynamic therapy, state of the art review. Photodiagnosis and Photodynamic Therapy.v.5 n.1. 2008 p. 19 - 28.

2. ALVES, Luciana; BIANCHIN, Maysa Alahmar.O jogo como recurso de aprendizagem. Revista Psicopedagogia. São Paulo, vol. 27 n. 83, 2010.

3. BAUMAN, Zygmunt. Capitalismo parasitário. Tradução para o português de Eliana Aguiar. Rio de Janeiro: Zahar, 2010.

- Vida líquida. Tradução para o português de Carlos Alberto Medeiros. 2. ed. Rio de Janeiro: Zahar, 2009.

4. BECK, Ulrich. "A Reinvenção da Política: Rumo a uma Teoria da Modernização Reflexiva". IN: BECK, U.; GIDDENS, A. \& LASH, S. Modernização Reflexiva. São Paulo: Editora UNESP, 1997.

5. BECKER, F. Educação e construção do conhecimento. Porto Alegre; Artmed, 2001.

6. BÊRNI. Duilio de Avila. Teoria dos Jogos: jogos de estratégia, estratégia decisória, teoria da decisão. Rio de Janeiro: Reichmann \& Affonso Ed., 2004.

7. BONNER, F. T.; BURTON, J. D. Paulownia tomentosa (Thunb.) Sieb.\&Suec,.Royal paulownia. In: SCHOPMEYER, C. S. (Coord). Seeds of Woody plants in the United States. Washington: USDA-Forest Service, 1974. p. 572-573.

8. BOSSELMANN, Klaus. The principle of sustainability: transforming Law and governance. Surrey, England: Ashgate Publishing Limited, 2009.

9. CARRETERO, Mario. Construtivismo e Educação. Porto Alegre: Artes Médicas, 1997.

10. CHICK, Anne; MICKLETHWAITE, Paul. Design for Sustainable Change: How Design and Designer can drive the sustainability agenda. UK: AVA Publishing Ltd., 2011.

11. CROSS, N; CHRISTIAANS, H; DORST, K. Analysing Design Activity. Chichester: Wiley, 1996. 
12. ELKONIN, Daniil B. Psicologia do Jogo. São Paulo: Martins Fontes, 1998.

13. FLICK, Uwe. Desenho da pesquisa qualitativa. Porto Alegre: Artmed, 2009.

Qualidade na pesquisa qualitativa. Porto

Alegre: Artmed, 2009.

14. FRY, Tony. Design as politics. New York, NY: Berg, 2011.

15. FULLERTON, Tracy. Game Design Workshop: A playcentric approach to creating innovative games. Boca Raron, FL: CRC Press, 2008.

16. GOULART, Iris Barbosa (Org). A Educação na Perspectiva Construtivista. Petrópolis: Vozes, 1997.

17. KISHIMOTO, T. M. O Brincar e suas Teorias. São Paulo: Pioneira, 1998.

18. LORENZI, H. et al. Árvores Exóticas no Brasil: madeiras, ornamentais e aromáticas. Nova Odessa: Instituto Plantarum, 2003.

19. MANZINI, Ézio; VEZZOLI, Carlo. O desenvolvimento de produtos sustentáveis: os requisitos ambientais dos produtos industriais. São Paulo: EDUSP, 2002.

20. MORAVIA, W. G. et al. Caracterização microestrutural da argila expandida para aplicação como agregado em concreto estrutural leve. Cerâmica 52. 2006 p. 193 - 199.

21. PIAGET, Jean. O Nascimento da Inteligência da Criança. Rio de Janeiro: Zahar, 1982.

Psicologia e Pedagogia. Rio de Janeiro: Forense Universitária, 1976.

22. SAMPIERI, Roberto Hernández; COLLADO, Carlos Fernández; LUCIO, Pilar Baptista. Metodologia de la investigación. México: McGraw-Hill, 1991.

23. SANTAROSA, Lucila MariaCosti; CONFORTO, Débora. Formação de Professores em Tecnologias Digitias Acessíveis. Porto Alegre: Evangraf, 2012.

24. SILVERMAN, David. Interpretação de dados qualitativos: métodos para análise de entrevistas, textos e interações. 3. ed. Tradução Magda França Lopes. Porto Alegre: Artmed, 2009.
25. VEIGA, José E. A desgovernança mundial da sustentabilidade. São Paulo: Editora 34, 2013.

26. VEZZOLI, Carlo. Design de sistemas para a sustentabilidade: teoria, métodos e ferramentas para o design sustentável de "sistemas de satisfação". Salvador: EDUFBA, 2010. 